\title{
Conduction Band of Hematite Can Mediate Cytochrome Reduction by Fe(II) Under Dark and Anoxic Conditions
}

Tongxu Liu ${ }^{\mathrm{a}, \mathrm{b}}$, Ying Wang ${ }^{\mathrm{a}}$, Chongxuan $\mathrm{Liu}^{\mathrm{c}}$, Xiaomin $\mathrm{Li}^{\mathrm{d}}$, Kuan Cheng ${ }^{\mathrm{a}}$, Yundang $\mathrm{Wu}^{\mathrm{a}}$, Liping Fang Fangbai $\mathrm{Li}^{\mathrm{a}}{ }^{*}$, Chengshuai Liu ${ }^{\mathrm{a}}$

${ }^{a}$ Guangdong Key Laboratory of Agricultural Environment Pollution Integrated Control, Guangdong Institute of Eco-Environmental Science \& Technology, Guangzhou 510650, P. R. China

${ }^{\mathrm{b}}$ National-Regional Joint Engineering Research Center for Soil Pollution Control and Remediation in South China, Guangzhou 510650, China

c State Environmental Protection Key Laboratory of Integrated Surface Water-Groundwater Pollution Control, School of Environmental Science and Engineering, Southern University of Science and Technology, Shenzhen, 518055, P. R. China

d SCNU Environmental Research Institute, Guangdong Provincial Key Laboratory of Chemical Pollution and Environmental Safety \& MOE Key Laboratory of Environmental Theoretical Chemistry, South China Normal University, Guangzhou 510006, P. R. China

* Corresponding author:

Mailing address: No. 808 Tianyuan Road, Guangzhou 510650, P. R. China

Tel.: +8620 37021396. Fax: +862087024123.

E-mail: cefbli@soil.gd.cn

Main contents: 1 PDF (8 pages) of Supporting Methods, 10 figures (Figure S1 to Figure S10) 
Supporting Methods:

\section{S1. Quantification of reduced $c$-Cyts in hematite suspension.}

26 To avoid interference from the optical absorbance of hematite particles, a pure hematite 27 suspension without Fe(II) or $c$-Cyts was measured, so the baseline spectrum was subtracted from 28 all experimental data with hematite. The pure Fe(II) solution without $c$-Cyts was also measured 29 as a control for different treatments with $\mathrm{Fe}(\mathrm{II})$. The $\mathrm{Fe}$ (II) concentration was determined by the 30 1,10-phenanthroline method. The concentration of reduced $c$-Cyts at time $t\left(\mathrm{C}_{\mathrm{t}}\right)$ was calculated 31 from the measured absorbance (At) at $550 \mathrm{~nm}$ using the following equation (Eq. 1) after baseline 32 correction $^{1}$. $C_{\mathrm{t}}=\frac{A_{\mathrm{t}}-C_{0} \varepsilon_{\mathrm{ox}}}{\varepsilon_{\mathrm{ox}}-\varepsilon_{\mathrm{red}}}$ (Eq. 1)

34 where $\mathrm{C}_{0}$ is the initial concentration of oxidized $c$-Cyts, and $\varepsilon_{\mathrm{ox}}\left(8.4 \mathrm{M}^{-1} \mathrm{~cm}^{-1}\right)$ and $\varepsilon_{\text {red }}\left(29.5 \mathrm{M}^{-1}\right.$ $35 \mathrm{~cm}^{-1}$ ) are the molar absorption coefficients of the oxidized and reduced $c$-Cyts, respectively.

\section{S2. Reduction of $c$-Cyts by photogenerated electrons from hematite}

37 Preparation of Hem-FTO. Fluorine doped tin oxide (FTO) glass coated with Hem was prepared 38 following a simple hydrothermal method. ${ }^{2}$ Briefly, Two pieces of FTO glass $(2 \mathrm{~cm} \times 2.5 \mathrm{~cm})$ 39 were ultrasonically cleaned for $60 \mathrm{~min}$ in a mixture of deionized water, acetone, and 2-propanol 40 (1:1:1 in volume ratio), and then placed against the Teflon-lined wall with the $\mathrm{SnO}_{2}$-coated 41 side facing down. Next, $33.3 \mathrm{~mL}$ of a mixed solution containing $0.15 \mathrm{M} \mathrm{FeCl}_{3} \cdot 6 \mathrm{H}_{2} \mathrm{O}$ and $1 \mathrm{M}$ $42 \mathrm{NaNO}_{3}$ was transferred to a Teflon-lined stainless-steel autoclave (100 $\mathrm{mL}$ in volume). The 43 hydrothermal reaction was carried out at $100{ }^{\circ} \mathrm{C}$ for $12 \mathrm{~h}$ in an oven, and then the autoclave was 44 cooled to room temperature under ambient conditions. The coated glass samples were calcined at $45550{ }^{\circ} \mathrm{C}$ in air for $2 \mathrm{~h}$ with a ramp of $2{ }^{\circ} \mathrm{C} \mathrm{min}{ }^{-1}$, taken out, rinsed well with deionized water and 46 ethanol, and finally dried in dinitrogen gas. The crystal structure was characterized as the typical 47 pattern of hematite (Figure S2).

48 Photochemical experiments. A $c$-Cyts solution $(10 \mathrm{~mL}, 6.5 \mu \mathrm{M})$ in $30 \mathrm{mM}$ PIPES buffer $(\mathrm{pH}=$ 49 6.5) was added into a sealed glass container with the prepared Hem/FTO at the bottom. A UV 
50 lamp $(1 \mathrm{~W})$ as the light source was positioned $c a .5 \mathrm{~cm}$ away from the bottom of the container

51 (Figure S3a). A control experiment was carried out without light illumination. All experiments

52 were conducted under anoxic conditions by continuous purging with dinitrogen gas. The $c$-Cyts

53 was reduced by the photogenerated electrons under light illumination. Using a syringe, $3 \mathrm{~mL}$ of

54 the suspension sample was taken out every $1 \mathrm{~h}$ to examine the concentration of reduced $c$-Cyts,

55 and then the sample was injected immediately back into the reaction solution.

\section{S3. Characterization of solid samples}

57 Powder X-ray diffraction (XRD) patterns were obtained on a Smartlab 9kw X-ray 58 diffractometer (Rigaku, Japan) with $\mathrm{Cu} \mathrm{K \alpha}$ radiation $(\lambda=0.15418 \mathrm{~nm})$ at a speed $(2 \theta)$ of $10^{\circ}$

$59 \mathrm{~min}^{-1}$, and the accelerating voltage and the applied current were $40 \mathrm{kV}$ and $100 \mathrm{~mA}$, respectively.

60 The morphology observation was performed on a Hitachi SU8220 Field Emission scanning 61 electron microscope (FESEM, Hitachi, Japan) at an accelerating voltage of $10 \mathrm{kV}$. The solid 62 samples were examined with Mössbauer spectroscopy at $12 \mathrm{~K}$, using a WissEl Elektronik 63 (Germany) instrument with a closed-cycle cryostat SHI-850, a Sumitomo CKW-21 He 64 compressor unit, and an Ar-Kr proportional counter detector. A 57Co ( $50-\mathrm{mCi})$ source was 65 used as the gamma energy source. All spectra were calibrated against $7 \mu \mathrm{m} \alpha-\mathrm{Fe}(0)$ foil and fit 66 using Mosswinn software. 


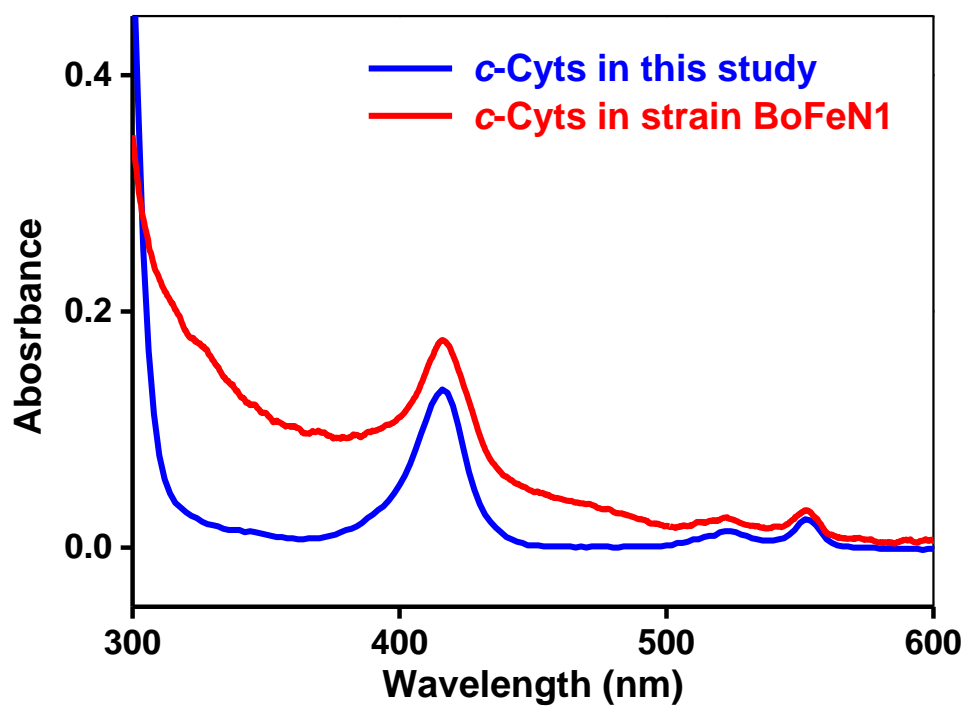

69 Figure S1. UV-Vis diffuse transmittance spectra of the $c$-Cyts used in this study and the living 70 cell suspension of Acidovorax sp. strain BoFeN1 $\left(\mathrm{OD}_{600}=0.8\right)$. Both of the spectra showed the 71 peaks at $415 \mathrm{~nm}$ and $550 \mathrm{~nm}$, which were ascribed to the heme $c$ group as the redox center of $72 c$-Cyts. The baseline for strain BoFeN1 was higher than $c$-Cyts in this study, because of the 73 scattering and absorbance of the cell surface. The Fe(II) oxidizing ability of $c$-Cyts in strain 74 BoFeN1 was reported in our previous paper (Liu et al., 2019). Hence, the commercial $c$-Cyts 75 could be used as a model protein in this study.

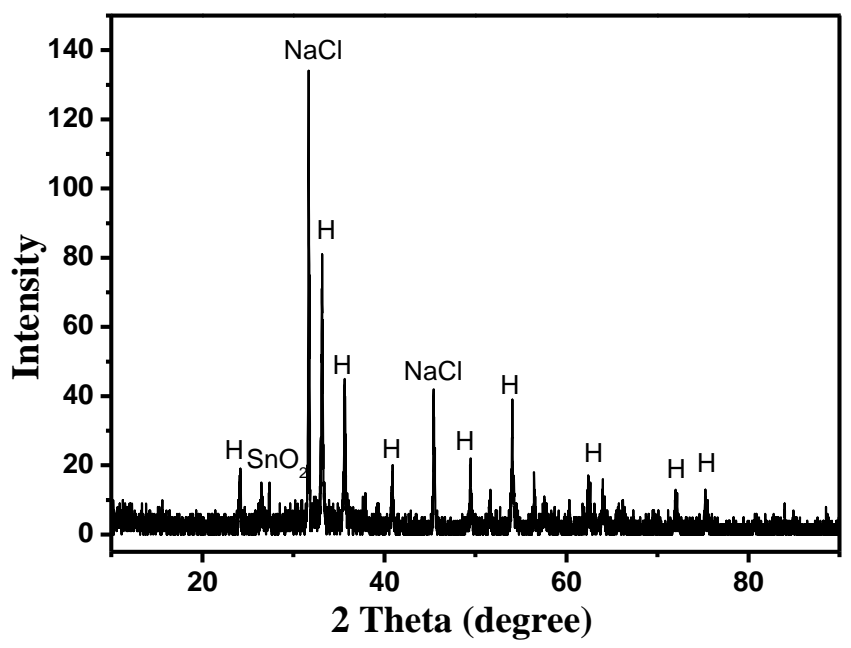

77 Figure S2. XRD pattern of the hematite coated FTO. "H" represents hematite. The peaks at 24.1, $7833.1,35.6,40.8,49.5,54.1,62.4$ and 64.0, corresponded to (012), (104), (110), (113), (024), 79 (116), (214) and (300) plane diffractions of $\alpha-\mathrm{Fe}_{2} \mathrm{O}_{3}$ (JCPDS no. 33-0664), respectively. 

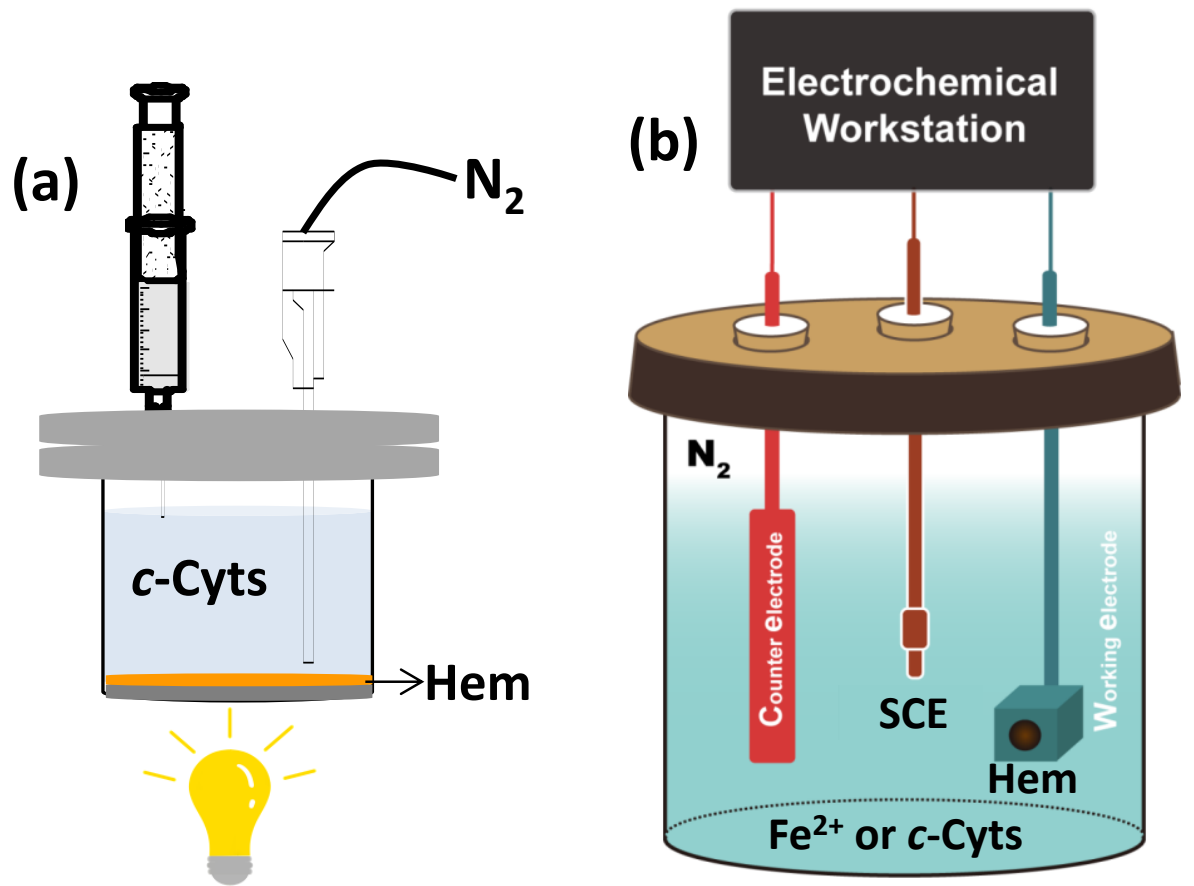

82 Figure S3. Schematic diagram of the (a) photochemical and (b) electrochemical reactors.

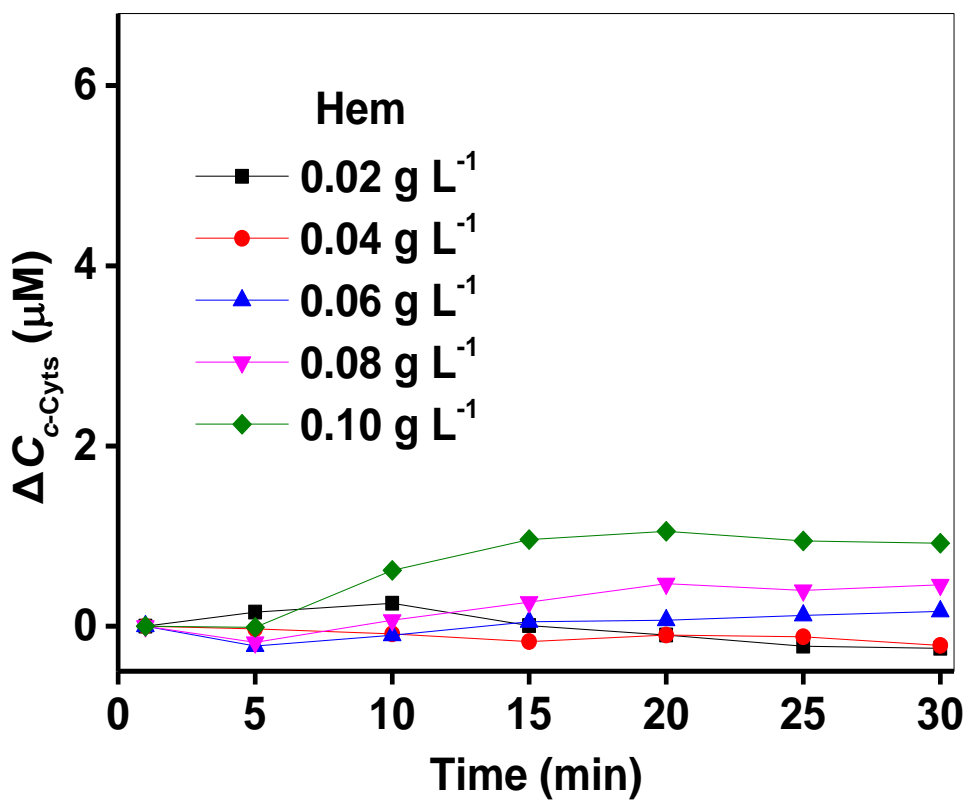

84 Figure S4. Time course of the adsorbed $c$-Cyts concentration with different hematite contents. 


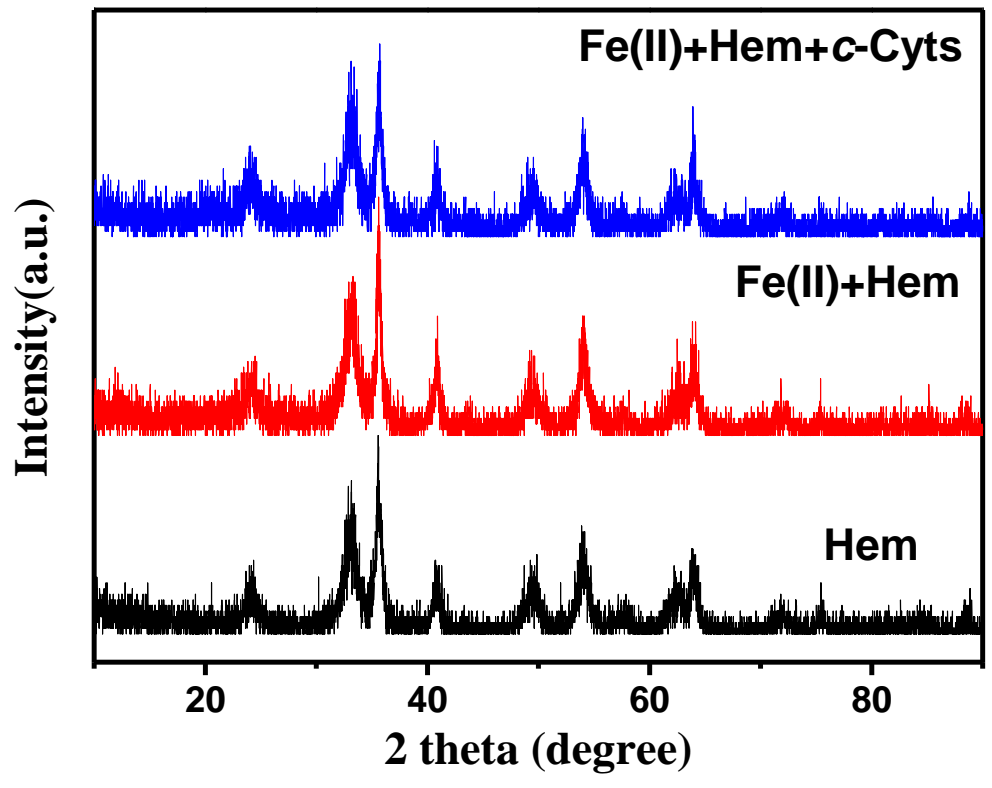

87 Figure S5. XRD patterns of the solid samples of hematite before and after reacting with $\mathrm{Fe}(\mathrm{II})$ 88 and $c$-Cyts. The treatments included Hem, $\mathrm{Fe}(\mathrm{II})+\mathrm{Hem}$, and $c$-Cyts+Fe(II)+Hem.
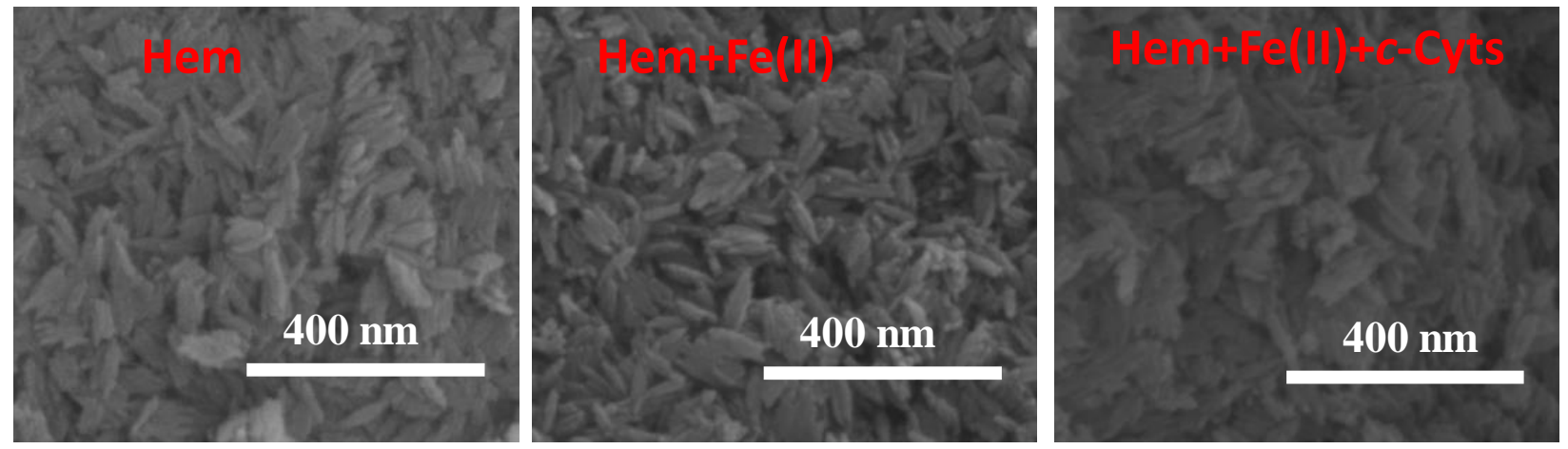

91 Figure S6. SEM images of the solid samples of hematite before and after reacting with Fe(II)

92 and $c$-Cyts. The treatments included Hem, $\mathrm{Fe}(\mathrm{II})+\mathrm{Hem}$, and $\mathrm{Fe}(\mathrm{II})+\mathrm{Hem}+c$-Cyts. 


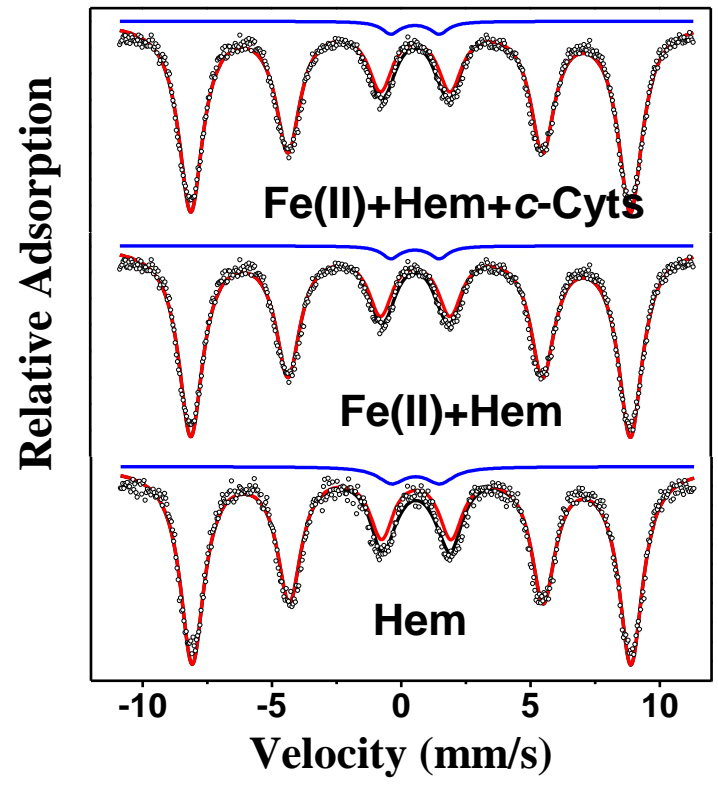

95 Figure S7. Fitted Mössbauer spectra of the solid samples of hematite before and after reacting 96 with $\mathrm{Fe}(\mathrm{II})$ and $c$-Cyts at $12 \mathrm{~K}$. The treatments included Hem, $\mathrm{Fe}(\mathrm{II})+\mathrm{Hem}$, and $97 \mathrm{Fe}(\mathrm{II})+\mathrm{Hem}+c$-Cyts.

98
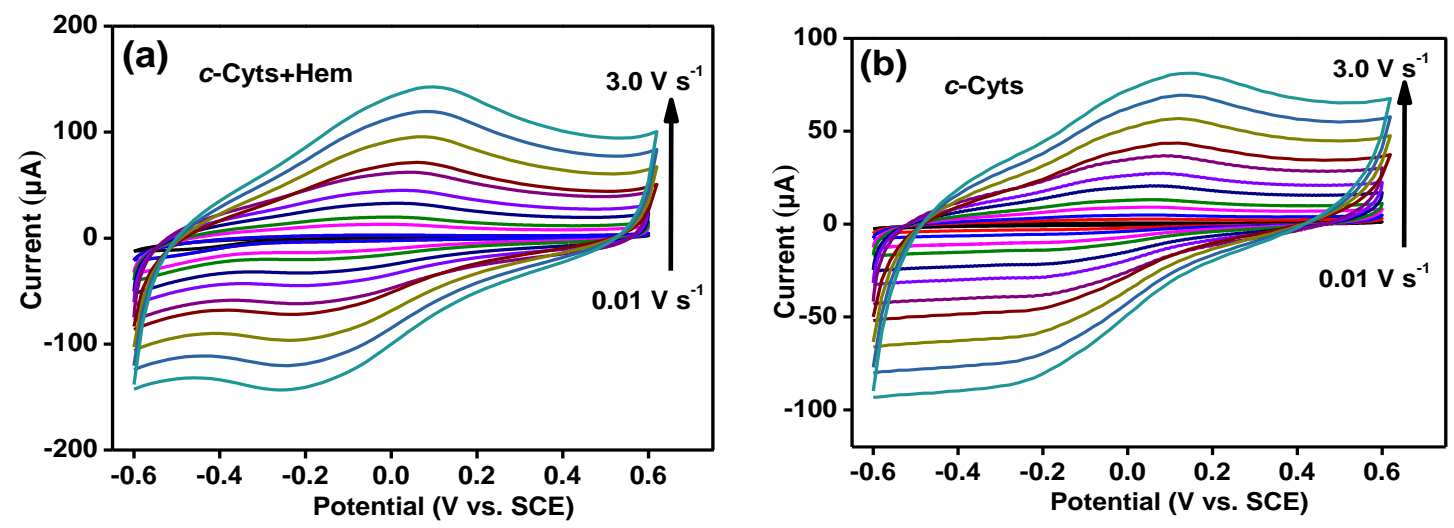

99 

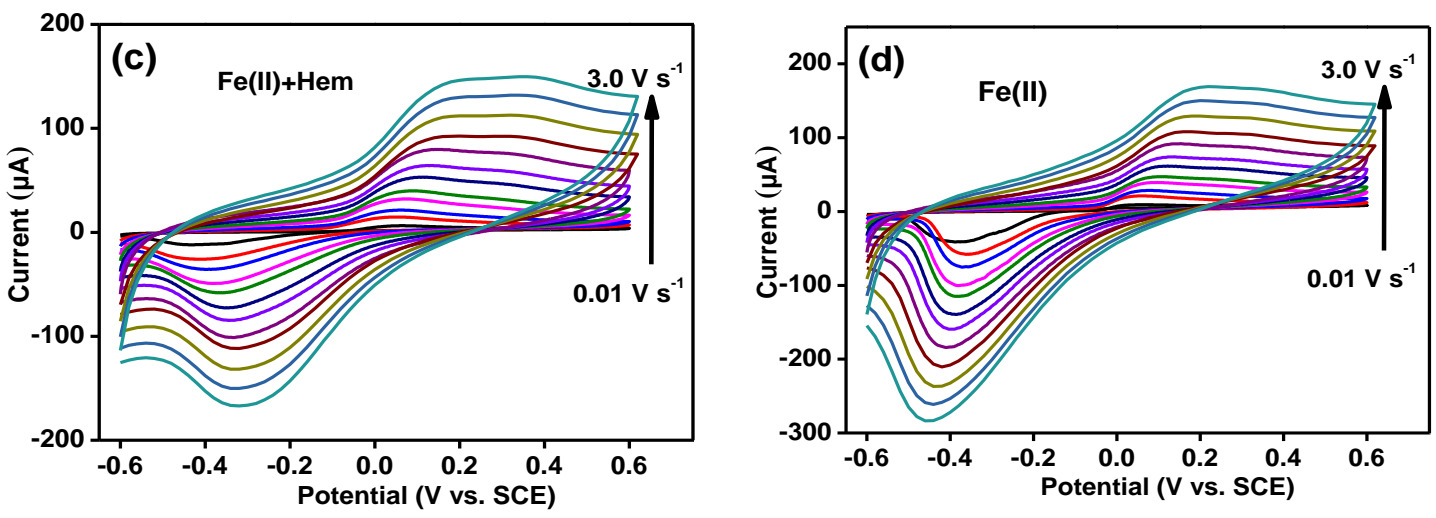

Figure S8. Cyclic voltammetry curves of $c$-Cyts and Fe(II) absorbed on the electrode (a, c) with and $(b, d)$ without hematite coating under different scan rates.

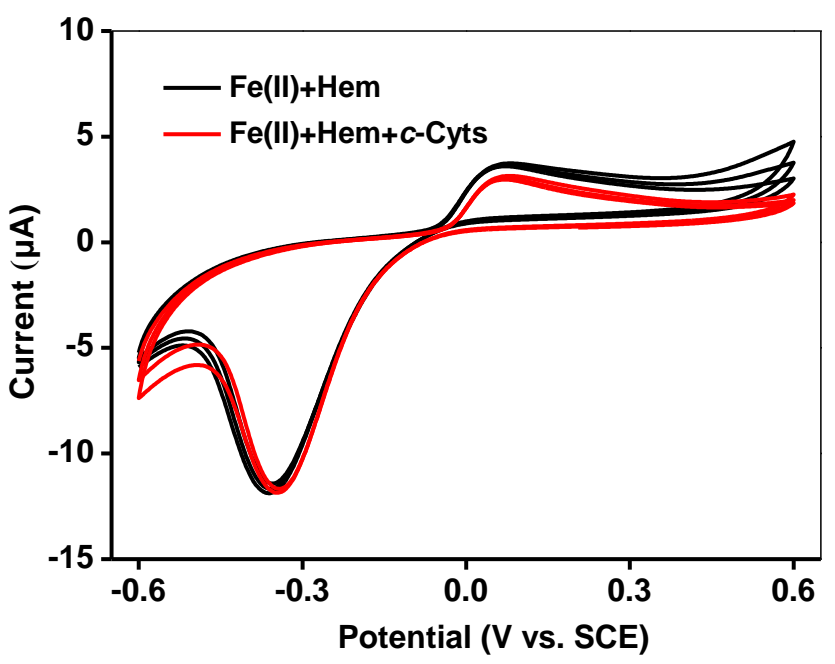

104 Figure S9. Cyclic voltammetry curves of $\mathrm{Fe}(\mathrm{II})+\mathrm{Hem}$ and $c$-Cyts+Fe(II)+Hem at different reaction time. 


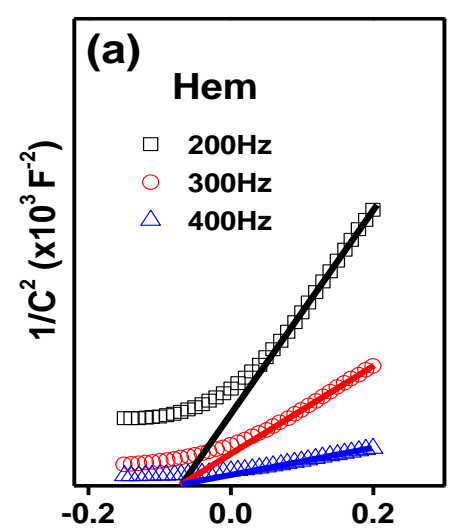

Potential (V vs. SCE)
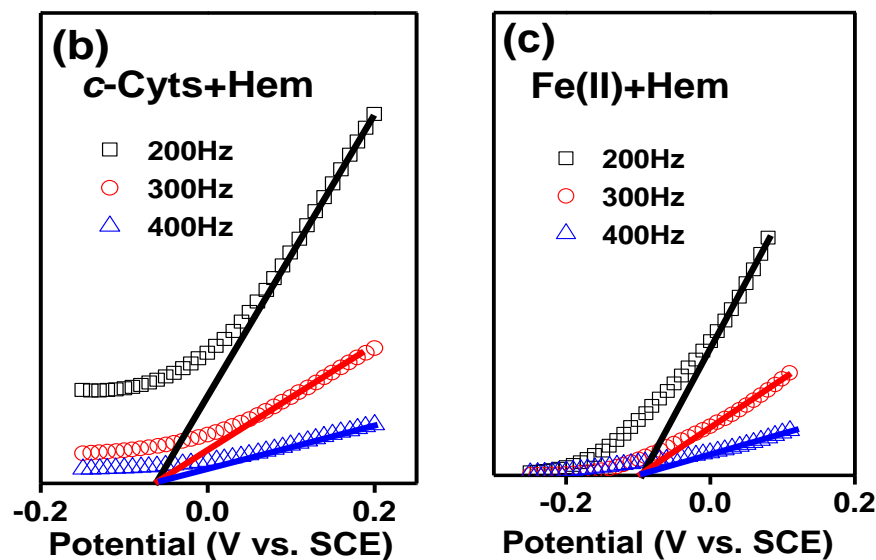

108 Figure S10. Mott-Schottky plots of hematite in the (a) absence or (b) presence of $c$-Cyts and (c) 109 $\mathrm{Fe}(\mathrm{II})$ at 200, 300, and $400 \mathrm{~Hz}$.

\section{References:}

112 (1) Wang Z., Liu C., Wang X., Marshall M. J., Zachara J. M. Rosso K. M., Dupuis M.,

113 Fredrickson J. K., Heald S. and Shi L. (2008) Kinetics of reduction of Fe (III) complexes by 114 outer membrane cytochromes MtrC and OmcA of Shewanella oneidensis MR-1. Appl. Environ. 115 Microb., 74, 6746-6755.

116 (2) Vayssieres, L.; Beermann, N.; Lindquist, S. E.; Hagfeldt, A. Controlled aqueous chemical

117 growth of oriented three-dimensional crystalline nanorod arrays: application to iron(III) oxides.

118 Chem. Mater., 2001, 13(2), 233-235. 